University of Nebraska - Lincoln

DigitalCommons@University of Nebraska - Lincoln

Publications from USDA-ARS / UNL Faculty

U.S. Department of Agriculture: Agricultural

Research Service, Lincoln, Nebraska

2005

Sampling For PM10 and PM2.5 Particulates

R. L. Pfeiffer

USDA-ARS-NSTL

Follow this and additional works at: https://digitalcommons.unl.edu/usdaarsfacpub

Pfeiffer, R. L., "Sampling For PM10 and PM2.5 Particulates" (2005). Publications from USDA-ARS / UNL Faculty. 1393.

https://digitalcommons.unl.edu/usdaarsfacpub/1393

This Article is brought to you for free and open access by the U.S. Department of Agriculture: Agricultural Research Service, Lincoln, Nebraska at DigitalCommons@University of Nebraska - Lincoln. It has been accepted for inclusion in Publications from USDA-ARS / UNL Faculty by an authorized administrator of DigitalCommons@University of Nebraska - Lincoln. 


\title{
Sampling For PM10 and PM2.5 Particulates
}

\author{
R.L. PFEIFFER \\ USDA-ARS National Soil Tilth Laboratory \\ Ames, Iowa
}

\section{INTRODUCTION}

\section{Physical Characteristics and Sources}

Particulate matter is the term given to the tiny particles of solid or semi-solid material found in the atmosphere. Particulates in the atmosphere range in size across many orders of magnitude. The expression "particulate size" is based on particle behavior in the earth's gravitational field. The aerodynamic equivalent diameter refers to a spherical particle of unit density $\left(1 \mathrm{~g} \mathrm{~cm}^{-3}\right)$ that falls at standard velocity. Size, because it determines atmospheric lifetime and lung deposition, is a very important characteristic of particulates. Particulates ranging in size from $<0.1$ to $50 \mu$ are called Total Suspended Particulates (TSP). Particulates larger than $50 \mu$ tend to settle out of the air whereas particulate matter $10 \mu$ in diameter and smaller are considered inhalable. This particulate matter is commonly referred to as PM10.

The terms "fine" and "coarse" were originally intended to apply to the two major atmospheric particle distributions that overlap in the size range between 1 and $3 \mu$ diameters. Currently, fine is referred to as PM2.5 (particulates with a diameter $<2.5 \mu$ ) and coarse as PM10 (particulates with a diameter $<10 \mu$ ).

By far, the majority of man-made particulates are in the 0.1 to $10 \mu$ diameter range. Particulates larger than $10 \mu$ are usually due to sand and dirt blown by winds from a variety of sites and usually contain large amounts of silica. The chemical complexity of airborne particles requires that the composition and sources of a large number of primary and secondary components be considered (USEPA, 1996). Primary particulates are emitted directly into the atmosphere from a variety of sources. Secondary particulates are formed in the atmosphere as a result of chemical processes. Major components of PM2.5 particles are sulfate, strong acids, ammonium, nitrate, organic compounds, trace metals, elemental carbon, and water. Sulfur dioxide, nitrogen oxides, and certain organic compounds are major precursors of fine secondary particulate matter. Nitric oxide reacts with ozone to form nitrogen dioxide. Sulfur dioxide and nitrogen dioxide react with the hydroxyl radical to form sulfuric and nitric acid, respectively. Nitrogen dioxide also reacts with ozone to form nitric acid through a sequence of reactions involving the nitrate radical. These acids may

Copyright (C2005. American Society of Agronomy, Crop Science Society of America, Soil Science Society of America, 677 S. Segoe Rd., Madison, WI 53711, USA. Micrometeorology in Agricultural Systems, Agronomy Monograph no. 47. 
react with ammonia to form ammonium sulfates and nitrates. Some types of higher molecular weight organic compounds react with hydroxyl radicals to form oxygenated organic compounds that can condense onto existing particles. Sulfur dioxide dissolved in clouds and fog droplets may react with ozone, hydrogen, and oxygen to form sulfuric acid or sulfates that lead to particulates when the water evaporates. The formation of secondary particulate matter depends on reactions between species which are normally present in the atmosphere but that occur in higher concentrations during smog. Since smog formation increases with temperature and sunlight, secondary particulate matter peaks during the summer months in most areas of the USA. Natural sources of fine particulate matter include wind blown dust, sea salt, particulates formed from the oxidation of sulfur compounds emitted from the oceans and wetlands, oxidation of nitrogen oxides from natural forest fires and lightning, and the oxidation of hydrocarbons such as terpenes emitted by vegetation. Figures 11-1 and 11-2 (USEPA, 1998b) show the PM2.5 concentrations in the western and eastern USA, respectively. The contributions of organic carbon, sulfate, crustal material, nitrate, and elemental carbon to the total PM2.5 are also depicted in these figures.

PM10 particulates (coarse) are generally emitted from sources, such as vehicles, materials handling, and crushing and grinding operations, as well as windblown dust as shown in Fig. 11-3 (USEPA, 1998b). PM10 particulates contain a large percentage of elemental and organic carbon, and play a major role in haze and health effects. The major components of coarse particulate matter are aluminoslicates and other oxides of crustal elements such as iron, calcium, etc, fugitive dust from roads, industry, agriculture, construction, demolition, and fly ash (USEPA, 1998). The levels of PM10 vary among urban, suburban, and rural areas as shown in Fig. 11-4 (USEPA, 1998b).

The atmospheric transport and fate of airborne particulates differ widely (Godish, 1997). Dry deposition of fine particles is slow. Primary and secondary

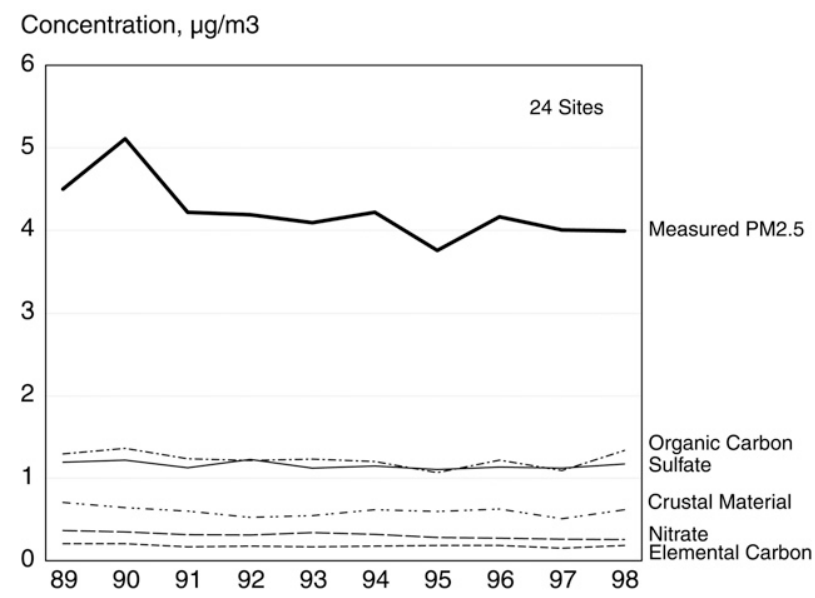

Fig. 11-1. PM2.5 concentrations at western sites. 


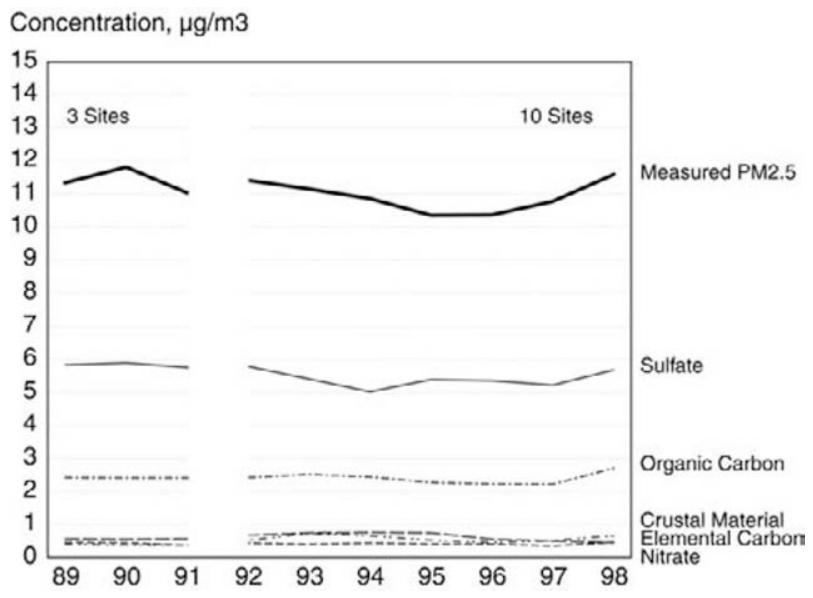

Fig. 11-2. PM2.5 Concentrations at eastern sites.

fine particles have long lifetimes in the atmosphere (days to weeks) and travel long distances. As a result, they are not easily traced back to their sources. Coarse particles have shorter lifetimes $(<24 \mathrm{~h})$ and travel short distances $(<100 \mathrm{~km})$. Fine particles tend to be distributed uniformly across a large area whereas course particles tend to be unevenly distributed even across very short distances.

\section{Health and Welfare Effects}

Particulates inhaled by humans are segregated by size during deposition in the respiratory system. The smaller the particulate the deeper is the penetration into the lungs and the longer is the period of retention.

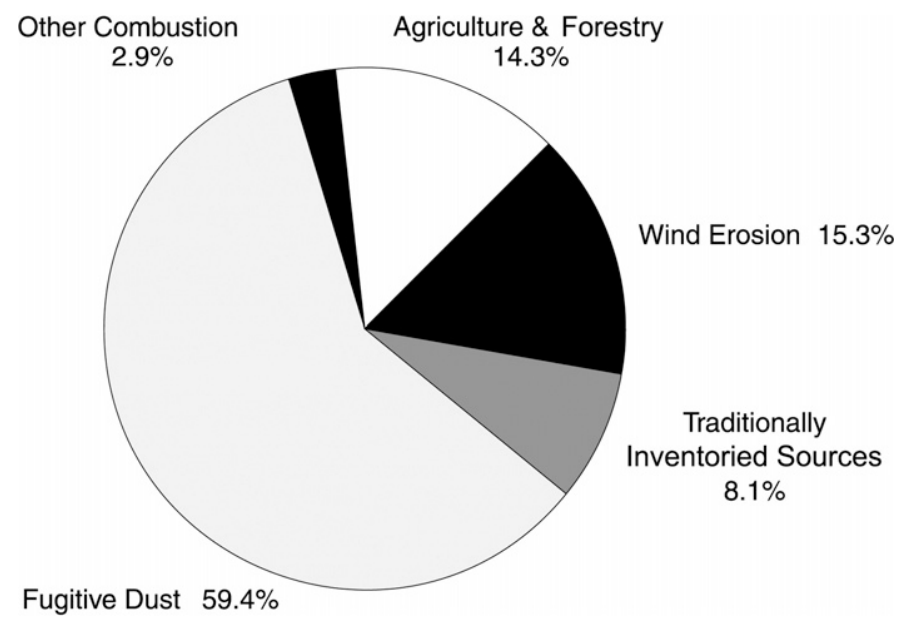

Fig. 11-3. Total PM10 emissions by category, 1998. 


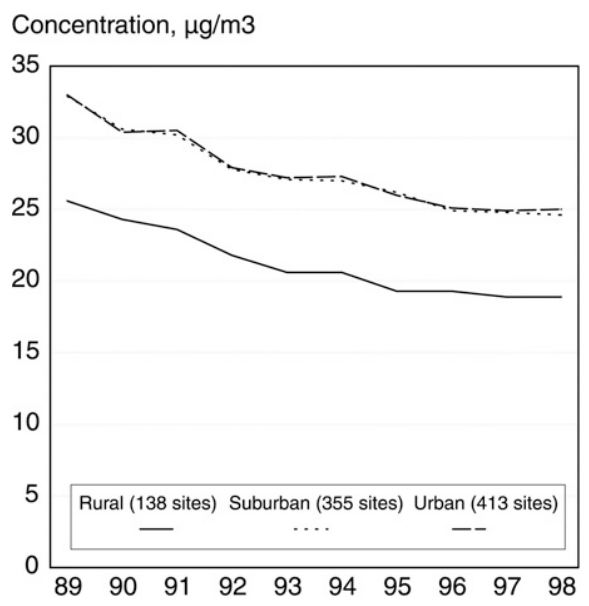

Fig. 11-4. PM10 Annual mean concentrations trends by location.

An alternative route of toxicity from particulate exposure is via mucous that when swallowed allows particulates to reach the stomach. Such a mechanism is the primary route for atmospheric lead to enter the body and manifest its toxicity. Pollutants in the air also interact resulting in synergistic affects. An example of this is the interaction of PM10 and sulfur dioxide. Sulfur dioxide is normally removed in the upper respiratory system, but adsorption-absorption of sulfur dioxide onto particulates allows for the penetration of sulfur dioxide deep into the pulmonary system where sulfur dioxide toxicity can occur (Godish, 1997). Exposure to coarse particles is primarily associated with the aggravation of respiratory conditions, such as asthma. Fine particles are most closely associated with health effects such as increased hospital admissions and emergency room visits due to heart and lung disease, increased respiratory symptoms and disease, decreased lung function, and even premature death (Shprentz, 1996). Sensitive groups that appear to be at greatest risk include the elderly, individuals with cardiopulmonary disease, and children (USEPA, 1996b). Increased levels of particulates in the air cause premature deaths and lead to more hospitalizations of elderly people who have chronic heart and lung disease according to a study released by the Health Effects Institute in Cambridge, MA (Sart et al., 2000). This study found a $0.5 \%$ increase in the overall death rate for each $10 \mu \mathrm{g} \mathrm{m}^{-3}$ increase in PM10. In addition, the study found a $1 \%$ increase in hospital admissions for cardiovascular disease and a $2 \%$ increase for pulmonary disease and pneumonia for each $10 \mu \mathrm{g} \mathrm{m}^{-3}$ increase in those people 65 years of age and older.

\section{Historical Perspective}

Air quality regulations first appeared in the early 1900s when a number of large U.S. cities attempted to control smoke originating from many new industries. These were very minimal in nature and it was not until the 1950 s that serious attempts to control air quality appeared. These more drastic controls were in 
response to the severe smog problems in California. In the 1960s there was an increased recognition at all government levels that air pollution was a problem, and this led to the onset of the environmental movement in the USA in the early 1970s.

In 1971, the U.S. Environmental Protection Agency (USEPA) promulgated primary and secondary national ambient air quality standards for particulate matter measured as total suspended particulate or TSP. In 1984, the USEPA in accordance with the Clean Air Act reviewed and revised the health and welfare criteria upon which this standard was based. PM10 replaced TSP as the indicator for particulate matter in the new ambient air quality standards. The Reference method for the measurement of PM10 is based on the selection of particulates of size $<10$ $\mu$ by internal separation followed by filtration and gravimetric determination of the mass of particulates on the filter substrate. The ambient standards for PM10 were set at 50 and $150 \mu \mathrm{g} \mathrm{m}^{-3}$ for annual and 24-h averages, respectively (Code of Federal Register, 1987).

These PM10 standards where in place until 1997 when the USEPA proposed revised particulate matter standards that at this time are still only "proposed" (Code of Federal Register, 1997). The USEPA is revising the primary (health-based) PM standards by adding a new annual PM2.5 standard set at $15 \mu \mathrm{g}$ $\mathrm{m}^{-3}$ and a new 24-h PM2.5 standard set at $65 \mu \mathrm{g} \mathrm{m}^{-3}$. The USEPA as set the PM2.5 standards with a 24-h and annual averaging time to protect against effects of short- and long-term exposure identified in community studies. For the annual standard, areas will be in compliance with the new standards when the 3-yr average of the annual arithmetic mean PM2.5 concentrations from single or multiple community-oriented monitors is less than or equal to $15 \mu \mathrm{g} \mathrm{m}^{-3}$. For the new 24-h standard the form is based on the 98th percentile of 24-h PM2.5 concentrations in a year (averaged across $3 \mathrm{yr}$ ), at the population-oriented monitoring site with the highest individual measured value in the area. The USEPA, although maintaining the PM10 standard, did modify the $24-\mathrm{h}$ standard by replacing the " 1 -expectedexceedance" with a 99th percentile form, averaged across 3 yr to protect against short-term exposure to coarse fraction particles.

\section{PRINCIPLES OF OPERATION}

\section{Methodology}

The methodology for the collection and mass determination of particulate matter is rather simple. Air is drawn through a size-selective inlet and through some sort of filter media. Particulates with aerodynamic diameters less than the cut-point of the inlet are collected on the filter media. The mass of these particulates is determined by the difference in filter weight before and after sampling. The concentration of the suspended particulate matter in the designated size range is calculated by dividing the weight gain of the filter by the volume of the air sampled.

There are many manufacturers of a variety of particulate samplers ranging from individual dosimeters to fully automated continuous units. Regardless of the 
type of sampler, they all have in common a size selective inlet, a filter or other mechanism to trap the particulates, and a means of pulling air through the system. The primary method for PM10 uses a sampler that draws air through a 20.3 $\times 25.4 \mathrm{~cm}$ ( $8 \times 10$ in) filter at a flow rate that is typically $1132 \mathrm{~L} \mathrm{~min}^{-1}$ (Lodge, 1989). This is referred to as a high volume sampler and is often used when chemical analysis is to be done on the trapped particulate or to maintain a continuous record. An Andersen High Volume Sampler, Model 321B (Andersen Instrument, Inc., Smyrna, GA) as shown in Fig.11-5 is discussed in detail as a representative PM10 sampler. Not all high volume particulate matter samplers are the same, but the principles involved are very similar and so a discussion of a representative sampler gives the reader a good understanding of how high volume particulate matter samplers function. The discussion includes how the samplers operate, calibration procedures, required maintenance, location requirements, proper handling and storage of filters, and finally, the determination of the mass of particulate matter per unit volume. QA/QC is so important that a section later in the chapter is dedicated to it.

PM2.5 low volume samplers are similar to the PM10 high volume samplers in that they also have a size selective inlet, a filter, and a means of pulling air through the system; however, the PM2.5 samplers have some unique characteristics. The size selective inlet is comprised of two separate size selective inlets: the first is a PM10 inlet to remove all the larger particulates followed by a PM2.5 selective inlet to exclude the particulates greater in diameter than $2.5 \mu$. A WINS (Well Impactor Ninety Six) is the USEPA recommended size selective inlet for PM2.5 isolation. The large glass fiber filter used in PM10 instrumentation is replaced by a $47 \mathrm{~mm}$ diameter Teflon filter. PM2.5 filters are used mainly for particulate mass determinations and not characterizations as are the larger PM10 filters. Particulate characterization is still done in conjunction with PM2.5, but species specific traps such as denuders, foam plugs, cation and anion exchangers, absorbents, etc., are used. The Andersen PM2.5 Speciation Sampler is shown in Fig. 11-6. The flow rate is $16.67 \mathrm{~L} \mathrm{~min}^{-1}$ generated by a vacuum pump that lasts up to 10000 hours of usage without maintenance. This is a significant improvement across most high volume sampler motors that require regular maintenance and/or replacement every 300 to $600 \mathrm{~h}$. Most PM2.5 samplers are under microprocessor control that uses real time temperature and barometric pressure readings to determine the actual flow rate, not estimations as with PM10 flow rate determinations. The added sophistication requires additional QA/QC to ensure that the automated systems are functioning properly.

Due in large part to the smaller filter and lower flow rates, PM2.5 samplers can be equipped with a variety of size selective inlets. The Partisol Air Sampler from Rupprecht \& Patashnick Company (Albany, NY) can be equipped with a PM1, PM2.5 sharp cut cyclone, PM2.5 with WINS impactor, PM10, United States TSP, or German TSP inlet for particulate analysis. The smaller filter used in PM2.5 samplers allows for advanced automation whereby a filter can be used and a replacement filter automatically put into position for another sampling period. Both the Partisol line from Rupprecht \& Patashnick and the RAAS line from Anderson have this capability. In addition, PM2.5 samplers can be equipped with an automatic weighing system for continuous real time analysis. The Series 

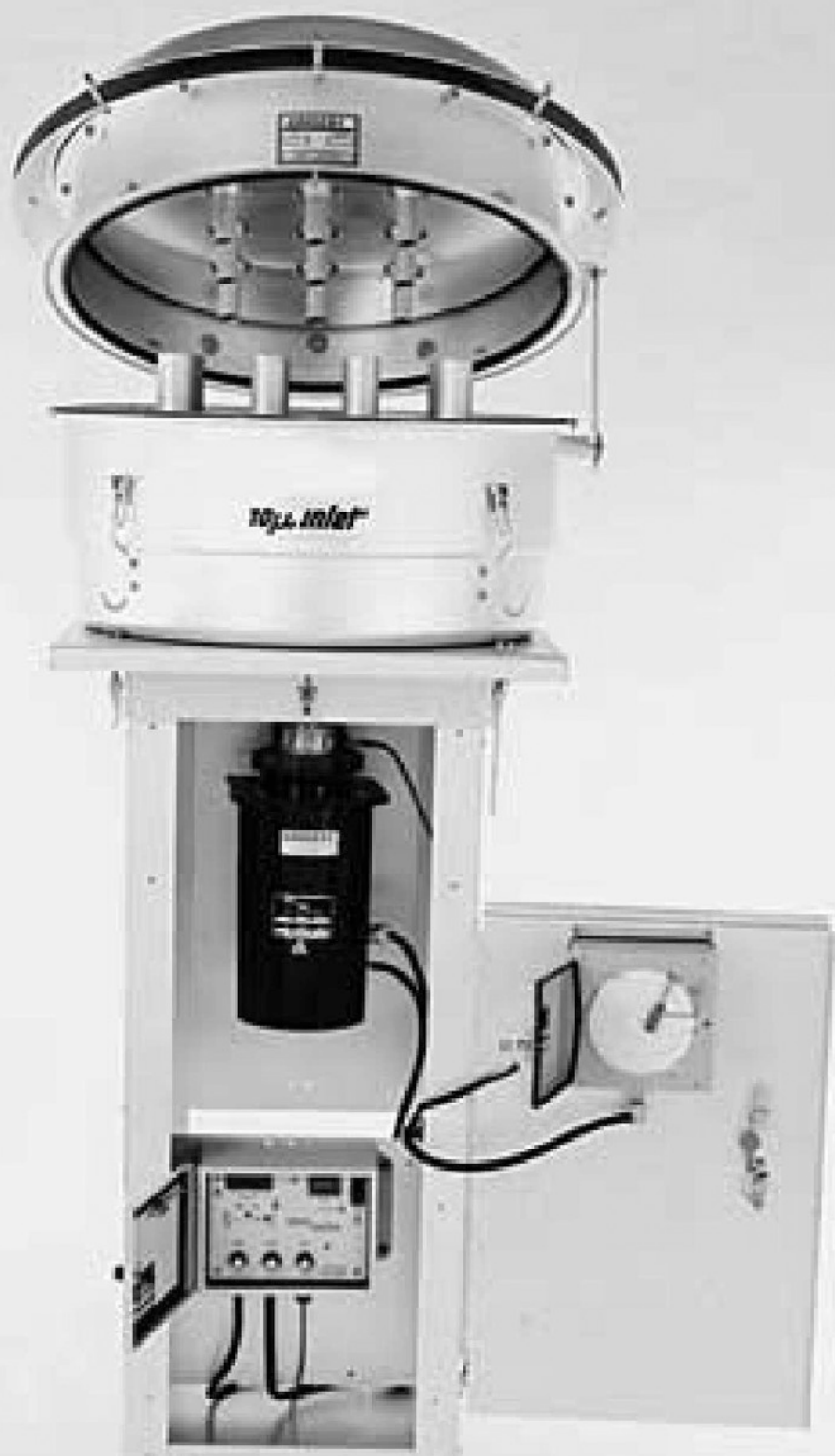

Fig. 11-5. Andersen PM10 high volume sampler. 


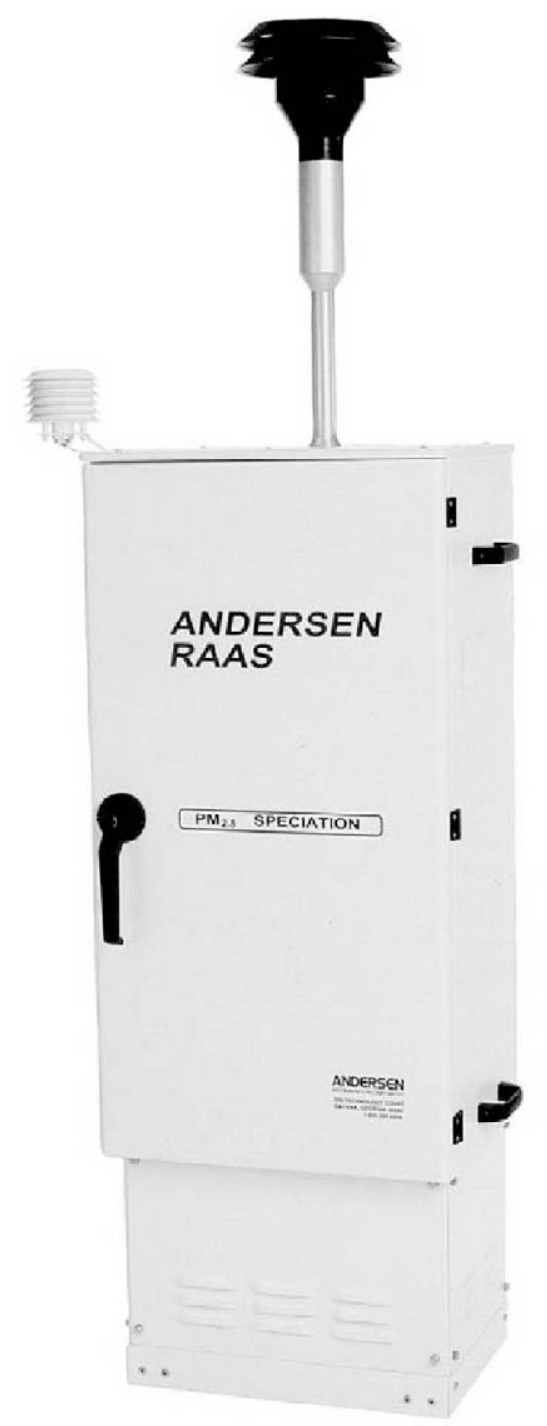

Fig. 11-6. Andersen PM2.5 speciation sampler.

1400 monitor from Rupprecht \& Patashnick incorporates an inertial balance that measures the mass collected on an exchangeable filter cartridge by monitoring the corresponding frequency changes of a tapered element. The sample flow passes through the filter where the particulate matter collects, and then continues through the hollow tapered element on its way to an electronic flow control system and vacuum pump. As more mass collects on the filter, the tube's natural frequency of oscillation decreases. A direct relationship exists between the tube's 
change in frequency and mass on the filter. This inertial methodology is a more fundamental means of measuring mass than the use of gravity. The tapered element technology enables highly precise and accurate mass determinations and rivals the resolution obtained from conventional microbalances.

\section{INSTRUMENTATION}

\section{Andersen High Volume PM10 Sampler with Mass Flow Control}

The major components of the Andersen High Volume PM10 sampler, Model 321B, are shown in Fig. 11-7 (Andersen Instruments, Inc., 1988). As ambient air is drawn into the inlet, it is evacuated from the buffer chamber where the particulates larger the $10 \mu$ are impacted onto a greased collection shim. The air is then accelerated through an additional 16 jets into a second impaction chamber. The acceleration nozzles have critical diameters to provide the necessary velocity to effect correct particulate size fractionation within the impaction chamber. The airflow finally exits the inlet through nine vent tubes onto a micro-quartz fiber filter.

Air is pulled through the filter into the intake of the motor and subsequently exits into the atmosphere. The actual mass flow rate of the sampled air is controlled with a reference/sensing flow probe mounted in the throat section of the filter holder. As ambient conditions or filter loading change, the controller increases-decreases the electrical power to the motor in such a manner that the

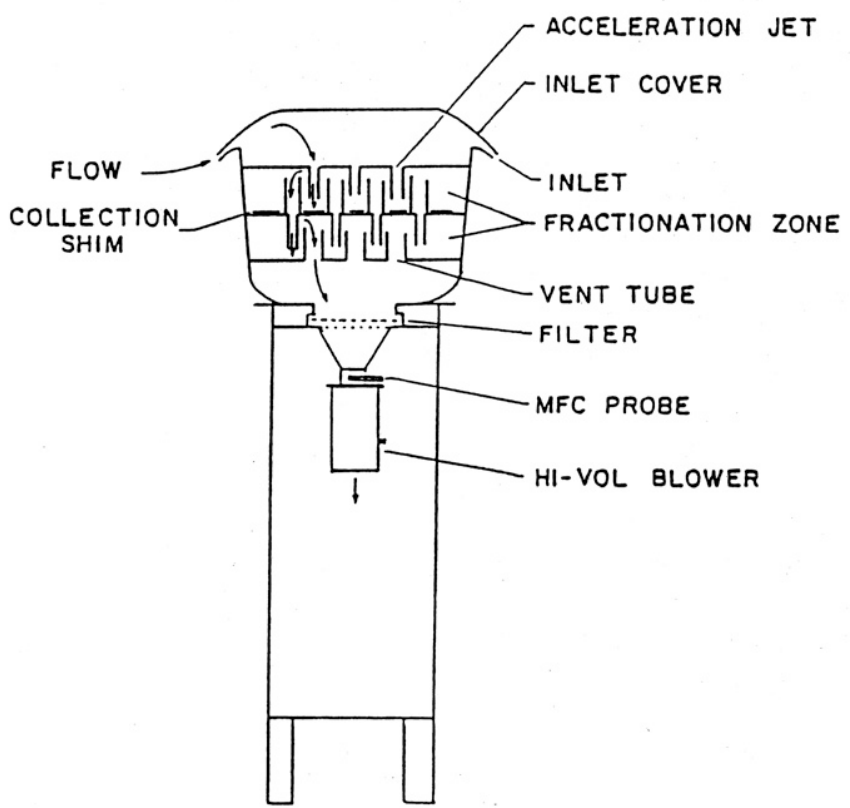

Fig. 11-7. Components of the Andersen high volume sampler. 
mass flow rate is maintained at a constant value that is set by adjusting a potentiometer following the sampler's calibration. The specific mass flow rate at which the sampler is set depends upon local conditions of temperature and barometric pressure. The Model 321-B is designed to maintain a $10 \pm 0.5 \mu$ cut point across a flow rate range of 1.02 to $1.24 \mathrm{~m}^{3} \mathrm{~min}^{-1}$. It is imperative that the operator chooses a set point that will center the flow rate with respect to fluctuating run temperatures and barometric pressure conditions so that as particulate is accumulated on the filter the flow controller will be able to maintain a flow rate within this range.

\section{Calibration Procedures}

Particulate size discrimination is dependent upon the air velocity through the acceleration jets. There are no field calibration standards for particulates, therefore an indirect method must be used. Calibration is very critical for proper instrument performance and requires the following equipment:

1. An orifice device for measuring flow rate that has been previously calibrated against a standard of known accuracy. The Streamline FTS from Rupprecht and Patashnick and the Vari-Flo from Andersen are two examples. Each of these orifice devices comes with a calibration relationship determined by plotting orifice pressure drop verses actual flow rate to find the slope $(m)$ and intercept $(b)$.

2. A manometer with a range from 0 to 16 inches of water and a minimum scale division of 0.1 inch.

3. A thermometer with a verified accuracy. All temperatures must be expressed in degrees Kelvin.

4. A barometer or other local verified source for barometric pressure. Pressures must be expressed in $\mathrm{mm} \mathrm{Hg}$ and must not be corrected to sea level (station pressure).

To perform the calibration on the Model 321-B, attach the orifice to the filter support. Calibration is done without a filter or filter cartridge in line. Disconnect the motor from the flow controller and plug it directly into a power source. Attach a water manometer to both the pressure tap on the orifice and the motor. If the sampler is equipped with a flow recorder attach it to the motor pressure tap instead of a manometer. A leak test must then be performed prior to calibration. Cover the inlet of the orifice calibration unit, close the manometer valves, and start the motor. Listen for a whistling sound that would indicate a leak in the system. Leaks are usually the result of a missing gasket or cross threading of the motor to the housing. Turn off the motor and open the manometer valves prior to calibration.

The sampler calibration procedure presented here relates known flow rates (as determined by the calibrated orifice) to the pressure differential across the exit orifice at the base of the motor. With the motor running and the calibration orifice fully open another reading is recorded for both manometers. The calibration orifice to closed slightly and a manometer reading is taken. This is repeated three more times for a total of five calibration points. Each of these points is repre- 
sented by a manometer reading from the calibration orifice and a manometer reading from the exit port of the motor. Calculations are performed as follows:

1. The flow rate through the calibration orifice is calculated using the following relationship:

$$
Q_{\mathrm{a}}=\left(\left(\Delta \mathrm{H}_{2} \mathrm{O} \times T_{\mathrm{a}} / P_{\mathrm{a}}\right)^{0.5}-b\right) / m
$$

Where $Q_{\mathrm{a}}=$ actual flow rate,

$b=$ intercept from orifice calibration relationship

$m=$ slope from orifice calibration relationship

$\Delta \mathrm{H}_{2} \mathrm{O}=$ orifice pressure differential

$T_{\mathrm{a}}=$ actual temperature in ${ }^{\circ} \mathrm{K}$

$P_{\mathrm{a}}=$ actual barometric pressure in $\mathrm{mm} \mathrm{Hg}$

2. Determine the $y$ value using the follow relationship

$y=\left(\Delta \mathrm{H}_{2} \mathrm{O} \times T_{\mathrm{a}} / P_{\mathrm{a}}\right)^{0.5}$

Where $\Delta \mathrm{H}_{2} \mathrm{O}=$ orifice pressure differential

$T_{\mathrm{a}}=$ actual temperature in ${ }^{\circ} \mathrm{K}$ at the time of calibration

$P_{\mathrm{a}}=$ actual barometric pressure in $\mathrm{mm} \mathrm{Hg}$

3. Plot the value of $y$ on the $y$-axis and the value of $Q_{\mathrm{a}}$ on the $x$-axis as shown on Fig. 11-8. Perform linear regression to determine the value of the intercept $(b)$, slope $(m)$, and the correlation coefficient. The correlation coefficient must be $>0.99$ for the calibration to be acceptable.

\section{Flow Rate Calibration}

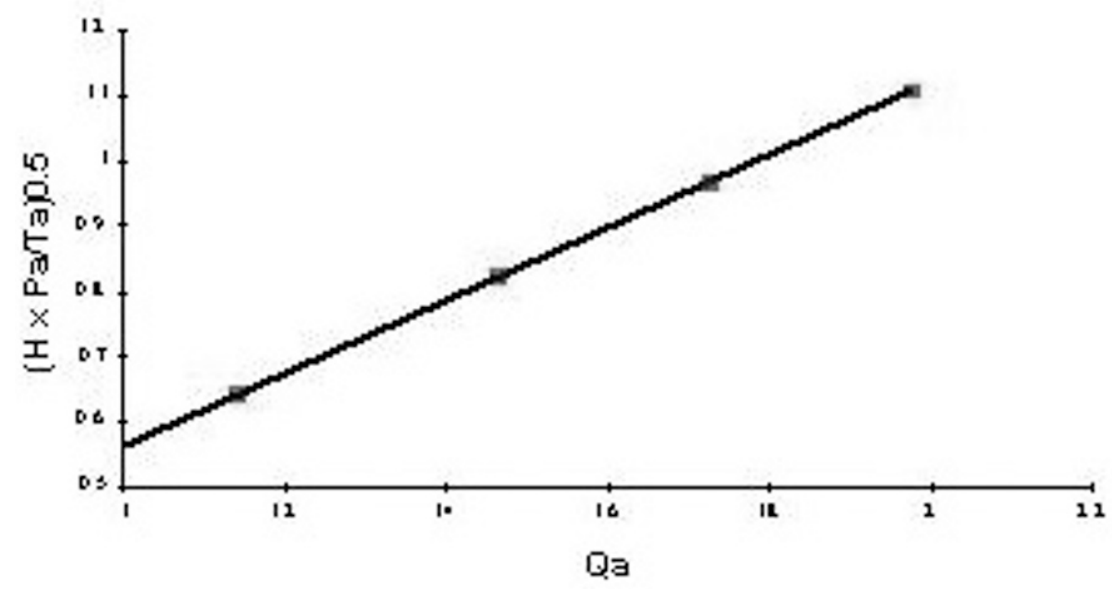

Fig. 11-8. Calibration plot. 


\section{Maintenance}

A regular maintenance schedule should be determined by usage and followed religiously to insure proper operation. In general, a thorough cleaning of the sampler should be done following $15 \mathrm{~d}$ of sampling. Maintenance should include the following:

- Inspect all hook-catches for proper tension.

- Clean all nozzles with a small test tube brush.

- Wipe all surfaces clean with a damp cloth or Kimwipe.

- Inspect and clean the shim. Recoat with silicone grease (Dow Corning 316 Silicone Release Spray) and allow at least $24 \mathrm{~h}$ for curing.

- Inspect all gaskets for wear and compression. Replace as necessary.

- Inspect filter holder and gaskets.

- The mass flow controller should operate without failure. The probe, however, should be cleaned with water followed by isopropyl alcohol using a small camel hair brush.

- Inspect the motor. Replace brushes and or motor according to manufacturer recommendations.

\section{Location}

Complete siting criteria can be found in 40 CFR 58 (Code of Federal Register, 1987). Minimum requirements are presented below:

- Sampler must be at least $20 \mathrm{~m}$ from trees, buildings, or other large obstacles. A general placement rule is that the sampler should be located at least twice as far away from the obstacle as the height of the obstacle.

- Sampler inlet should be 2 to $7 \mathrm{~m}$ above the ground.

- Sampler must have unrestricted air flow.

- Sampler inlet should be at least $2 \mathrm{~m}$ from any other high volume sampler.

- Do not place sampler directly upon the ground or gravel roof top.

- Do not place sampler near exhaust flues or vents.

- If filters are to be chemically analyzed, evaluate the site for potential contamination.

\section{Filter Preparation and Analysis}

The accuracy of a PM10 and sampling program depends on several factors. One of the most important of these factors is the procedure for handling and weighing the filter paper (USEPA, 1997). The following are guidelines for these procedures:

- Filter Handling: Quartz filter material is very fragile. Care must be taken not to tear the filters. A filter identification number must be assigned to each filter. Filters may be purchased with a number ID impregnated onto the filter or other tags may be attached. Filter have a 
rough side and a smooth side. The particulates are trapped on the rough side so it is always up. The labels should be on the smooth side to avoid confusion.

- Visual Inspection: All filters must be visually inspected for defects that include pinholes, loose material, discoloration, nonuniformity, and other irregularities.

- Filter Equilibration: Filters must be equilibrated in a conditioning environment for at least $24 \mathrm{~h}$ before being weighed. This can be done in an equilibration chamber or in an environmentally controlled weighing room. Relative humidity should be held constant at a mean value between 20 and $45 \% \pm 5 \%$. Temperature should be held constant with a mean value between 15 and $30^{\circ} \mathrm{C} \pm 3^{\circ} \mathrm{C}$.

- Initial Filter Weighing Procedures: Filters must be weighed on an analytical balance with a minimum resolution of $0.1 \mathrm{mg}$ and a precision of $0.5 \mathrm{mg}$. Make sure the balance is calibrated yearly according to manufacturer's specifications. Perform a "standard weight" check to verify performance. Tare the balance and weigh the filter paper, making sure that a stable reading is obtained. Return the weighed filters to their original box, identify up with a piece of tracing paper between filters. Record the weight checks, temperature, relative humidity, and filter weights in a spread sheet or other alternative data recording medium.

- Post-Sampling Documentation and Inspection: Upon receipt of exposed the filters from the field, laboratory personnel should verify that the filters are in good condition and that necessary data such as sampling time, average flow rate, average temperature and pressure is present. Make sure that the filter identity matches the laboratory record. Place the filters in a conditioning environment (chamber or controlled room) and equilibrate for $24 \mathrm{~h}$ before weighing.

- Final Weighing: Perform all calibrations as discussed in the previous section. Place the exposed filter on the balance, let stabilize, and record the final weight. Enter the final weight into the spread sheet or other data recording medium.

\section{Calculations, Validations, and Reporting of PM Data}

Measurements of mass concentrations are expressed in units of micrograms per cubic meter of air $\left(\mu \mathrm{g} \mathrm{m}^{-3}\right)$. Correction to standard conditions, i.e., $298^{\circ} \mathrm{K}$ and $760 \mathrm{~mm} \mathrm{Hg}$ are no longer required for particulate matter values (Code of Federal Register, 1997).

Particle size discrimination by inertial separation requires that specific air velocities be maintained in the sampler's inlet system. This actual flow rate $\left(Q_{\mathrm{a}}\right)$ must be measured at existing conditions of temperature $\left(T_{\text {av }}\right)$ and pressure $\left(P_{\text {av }}\right)$. The flow rate for the time period is calculated as follows:

$Q_{\mathrm{a}}=\left(\left(\Delta \mathrm{H}_{2} \mathrm{O} \times T_{\mathrm{av}} / P_{\mathrm{av}}\right)^{0.5}-b\right) / m$ 
Where $\quad Q_{\mathrm{a}}=$ the samplers average actual flow rate for the sampling period $\Delta \mathrm{H}_{2} \mathrm{O}=$ the average of the initial and final orifice pressure differential in inches $\mathrm{H}_{2} \mathrm{O}$

$T_{\mathrm{av}}=$ the average ambient temperature for the sampling period in ${ }^{\circ} \mathrm{K}$

$P_{\mathrm{av}}=$ the average barometric pressure for the sampling period in $\mathrm{mm}$ $\mathrm{Hg}$

$m=$ the slope of the sampler calibration relationship

$b=$ the intercept of the sampler calibration relationship

$T_{\text {av }}$ and $P_{\text {av }}$ readings may be recorded on site or estimated from data obtained from a nearby weather station. Pressure reading must be completed at the station and not adjusted to sea level. These seasonal (weekly, monthly, etc.) for the site may be used only when the actual values are within $20^{\circ} \mathrm{K}$ and $40 \mathrm{~mm}$ $\mathrm{Hg}$ of the seasonal averages.

\section{Calculations of PM10}

1. Calculate the total volume of air sampled using the following equation:

$$
V=Q_{\mathrm{a}} \times t
$$

Where $V=$ volume of air sampled

$Q_{\mathrm{a}}=$ average sampler flow rate across the sampling time

$t=$ total elapsed sampling time in minutes

2. Calculate the total PM10 concentration in $\mu \mathrm{g} \mathrm{m}^{-3}$ :

$$
\begin{aligned}
& \text { PM10 }=\left(W_{\mathrm{f}}-W_{\mathrm{i}}\right) \times 10^{6} / \mathrm{V} \\
& \text { Where PM10 }=\text { PM10 mass concentration } \\
& 10^{6}=\text { conversion factor for grams to micrograms } \\
& W_{\mathrm{f}}=\text { final weight of exposed filter } \\
& W_{\mathrm{i}}=\text { initial weight of unexposed filter } \\
& V=\text { volume of air sampled }
\end{aligned}
$$

\section{Andersen PM2.5 Low Volume Sampler with Mass Flow Control}

Figure 11-9 shows a flow schematic for the Andersen Speciation Sampler, Model RAAS2.5, from Andersen Instruments, Inc. (Andersen Instruments, Inc., 1999) The system pulls ambient air through an inlet with removes particulate matter $>10$ microns. The air sample is then directed via the downtube to the WINS Impactor that removes particulates of a diameter $>2.5$ microns. The particulate is collected on a $47 \mathrm{~mm}$ diameter Teflon filter. For automated systems, the single filter cassette is replaced by a filter selection mechanism allowing one of eight filters to be selected. The flow rate of the system is maintained at $16.67 \mathrm{~L}$ $\mathrm{min}^{-1}$ (ambient) by a digitally encoded dry gas meter and a diaphragm vacuum pump. Temperature and pressure corrections are made to correct for temperature 


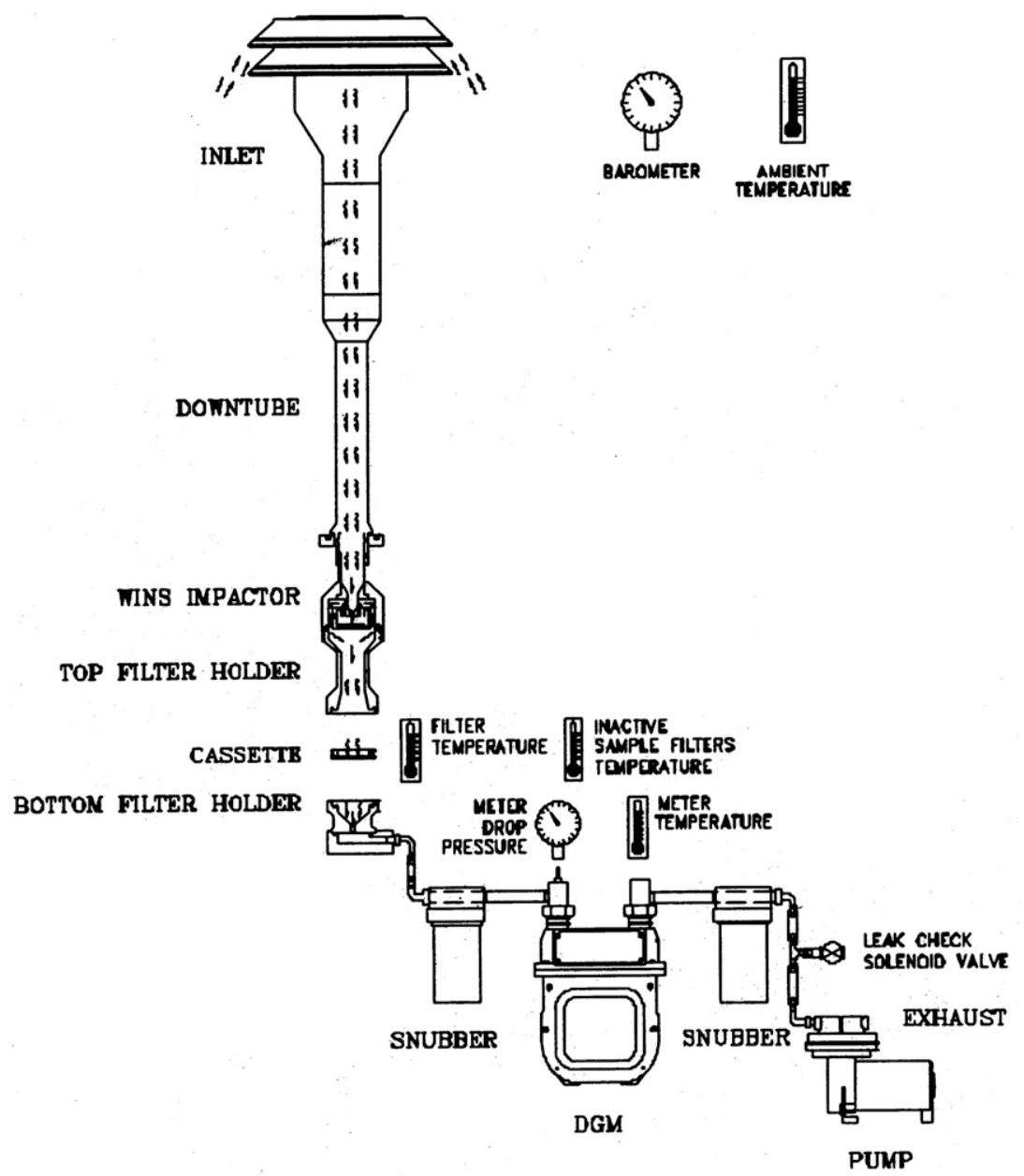

Fig. 11-9. Andersen PM2.5 speciations sampler components.

and pressure differences between ambient and dry gas meter conditions. The barometric pressure, meter drop pressure, ambient temperature, filter temperature, meter temperature, and inactive temperature also are recorded. The RAAS system is controlled by a user interactive microprocessor.

\section{Calibration Procedures}

The RAAS system requires periodic calibration for its pressure and temperature sensors and dry gas meter used for flow control. All calibration equipment must be National Institute of Standards and Technology (NIST) traceable. The digital thermocouple and thermometer must be accurate to $\pm 2{ }^{\circ} \mathrm{C}$. Pressure calibration is done using a pressure device with a range from 500 to $900 \mathrm{~mm} \mathrm{Hg}$ and an accuracy of $\pm 5 \mathrm{~mm} \mathrm{Hg}$ and a pressure changing device such as a syringe 
or hand pump. Flow calibrations are done with a NIST traceable dry gas meter with a readability of $0.0002 \mathrm{~m}^{3}$.

To calibrate each thermocouple, the reference thermocouple is attached to the selected sensor making sure that all other thermocouples are still connected. Using the software prompts the requested temperature information is entered into the computer. Two calibration points are required for calibration. The software stores the readings from the reference thermocouple and creates the calibration relationship for the sampler's thermocouple. The calibration thermocouple is disconnected and the sampler's thermocouple reinstalled. An alternate calibration procedure is to place the sampler's thermocouple and a calibration thermometer into a low temperature bath, allowed to equilibrate and the temperature entered into the calibration file. This is repeated at a high temperature to complete calibration of the thermocouple. Either method is done for each of the four thermocouples in the sampler.

Pressure calibration is done by measuring the change in pressure resulting from a pressure changing device such as a syringe and a calibrated pressure measuring device. Attach the two devices to the Ambient/Calibration port with $1 / 8$ " diameter tubing. Remove the pressure changing device to give a pressure reading of atmospheric pressure (about $765 \mathrm{~mm} \mathrm{Hg}$ ) noting the value of the pressure measurement device and recording it into the calibration file. Re-attach the pressure changing device and increase to pressure by approximately $200 \mathrm{~mm} \mathrm{Hg}$ and enter the value shown on the pressure measuring device. This should be repeated for each of the two pressure transducers on the sampler.

Flow rate calibration is critical and requires a calibrated dry gas meter. Attach the reference gas meter to the leak test adapter and open the valve. The sampler's dry gas meter and the reference meter will now be reading the same flow. Three different flow rates are generated by the sample's vacuum pump under software control. The corresponding volumes of air sampled are recorded by the reference gas meter and entered into the software by the operator. The sampler's software then generates the proper calibration data for the sampler's dry gas meter.

Leak testing must be done on the instrument to ensure that all air being pulled through the sampler enters via the impactor and not through a leak in the system The leak check adapter valve is put in the closed position and the sampler's vacuum pump is turned on to pump down the system. The dry gas meter should record less than $0.08 \mathrm{~L} \mathrm{~min}^{-1}$ if the system is leak free. If the test fails, isolate individual parts of the flow path to determine the source of the leak.

The RAAS's microprocessor allows for audit check on a routine basis. Attach a reference measuring device such as the thermometer, thermocouple or dry gas meter depending on which sensor you wish to check. Compare the values shown on the calibration equipment to that shown by the microprocessor. If values agree within manufacturers specifications, no further calibration is necessary.

\section{Maintenance}

Low volume samplers like high volume samplers are very rugged. They are designed to work in most environments. Low temperature operation may require the installation of additional heating units. Basic maintenance for the RAAS PM2.5 sampler includes: 
- Clean out dust from electronics modules.

- Verify calibration every $90 \mathrm{~d}$.

- Clean intake filter.

- Clean WINS Impactor, replace filter and add impactor oil.

- Perform vacuum pump maintenance.

\section{Location}

The location requirements for PM2.5 samplers are not significantly different than those requirements for PM10 samplers. This has been discussed previously so the requirements will not be repeated in this section.

\section{Filter Preparation And Analysis}

Filter handling is critical for PM2.5 analysis. Filters should be removed as soon as possible from the sampler and covered immediately. Filters need to be equilibrated in a controlled environment for $24 \mathrm{~h}$ before final weighing. The controlled environment requirements for PM2.5 are more conservative than for PM10. Temperature must be controlled at 20 to $23^{\circ} \mathrm{C}\left( \pm 2^{\circ} \mathrm{C}\right)$ and humidity must be controlled at 30 to $40 \%( \pm 5 \%)$. Weighing procedures for PM2.5 also are more conservative than for PM10. Since PM10 weighing procedures have been discussed previously, the following is a short summary of PM2.5 weighing procedures:

- All filters should be placed in a controlled environment for $24 \mathrm{~h}$ for both pre-sample and post-sample filters.

- Use the same analytical balance for all samples. Calibration guidelines are the same as for PM10.

- Filters must be used within $30 \mathrm{~d}$ of initial weighing.

- Post-sample filters must be weighed within $240 \mathrm{~h}$ of the end of sampling.

- Field blanks and lab blanks should be run routinely.

\section{Calculations for PM2.5}

$\operatorname{PM} 2.5=\left(W_{\mathrm{f}}-W_{\mathrm{i}}\right) / V_{\mathrm{a}}$

Where PM2.5 $=$ mass of PM2.5 in $\mu \mathrm{g} \mathrm{m}^{-3}$

$W_{\mathrm{i}},=$ initial weight in $\mathrm{mg}$

$W_{\mathrm{f}}=$ final weight in $\mathrm{mg}$

$V_{\mathrm{a}}=$ ambient volume of air sampled

For PM2.5, $V_{\mathrm{a}}$ is calculated by the sampler's microprocessor, not manually as for high volume PM10 analysis. Total sampling time must be between 23 and $25 \mathrm{~h}$ for the data to be valid.

\section{QA/QC}

Data validation is critical to any $\mathrm{QA} / \mathrm{QC}$ program. The data require to compute the mass concentrations, whether PM10 or PM2.5 originate from two 
sources of data: collection and calculation. These data must be validated to ensure that all reported PM values are accurate relative to the overall scope of the quality assurance program. To ensure proper QA/QC, total sampling times, average actual volumetric flow rates, tare and gross filter weights need to be checked for accuracy. All calculations also must be verified to ensure the final calculation is correct. The frequency of checks is dependent on the requirements of the QA/QC program and is critical as the values approach or exceed EPA limits.

Proper use and operation of the microbalances must be verified. Perform a "standard weight" check at the beginning of each weighing session. Values should agree within $0.5 \mathrm{mg}$ of actual value. Zero and calibration checks after every 5 to 10 filters have been weighed. Values should agree within $0.5 \mathrm{mg}$ of actual value. The operator should reweigh five to seven unexposed filters per weighing session. Values should agree within $\pm 2.8 \mathrm{mg}$. Because of the loss of volatile components, no definitive times are set for exposed filters; however, if the difference exceeds $\pm 5.0 \mathrm{mg}$, the weighing procedures need to be checked.

Instrument performance must be guaranteed. Calibration equipment must be NIST traceable and in good working order. Flow rate calculations depend heavily on proper measurements of temperature, barometric pressure, and manometer readings. Each of these must follow a predefined set of written guidelines to ensure proper values. Complete records must be kept, either electronically or in laboratory notebooks.

Personnel must be trained to follow exact procedures each and every time to ensure uniformity throughout the sampling time. They must be trained to question any suspected problem and to pursue proper investigative procedures to verify and correct any problems.

\section{APPLICATION TO AGRICULTURAL SYSTEMS}

What is the importance of measuring particulate concentrations in agricultural settings? Studies indicate that particulates are detrimental to human health, but most of those studies are centered around urban environments; however, the PM10 values shown in Fig. 11-4 indicate that the differences in exposures between urban and rural areas is not great. A report from the Natural Resources Defense Council (NRDC, 1) presents figures on the estimated annual cardiopulmonary deaths per 100000 population attributed to particulate air pollution is similar to the number of deaths from automobile accidents. This trend was true for cities such as Cedar Rapids, Des Moines, and Sioux City, IA, as well as other cities across the mid-west. Reducing particulate air pollution should be a component of any operation known to contribute to the mass of particulates found in the air.

\section{REFERENCES}

Godish, T.. 1997. Air quality. 3rd ed. CRC Press LLC, Bocoa Raton, FL.

Andersen Instruments, Inc. 1988. Instruction and operation high volume PM10 sampler. Andersen Instruments, Inc., Smyrna, GA. 
Andersen Instruments, Inc. 1999. RAAS operator's manual. Andersen Instruments, Inc., Smyrna, GA.

Lodge, J. (ed.) 1989. Methods of air sampling and analysis. 3rd ed. Lewis Publ., Chelsea, MI.

Code of Federal Regulations. 1987. Reference method for determination of particulate matter as PM10 in the atmosphere. Code of Federal Regulations, Parts 50, 51, 52, 53, and 58, Section 40. Federal Register, Vol. 52 (52).

Code of Federal Regulations. 1997. National primary and secondary ambient air quality standards. Code of Federal Regulations, Part 50, Section 40. Federal Register Vol. 62 (138).

Sart, J., S. Zeiger, F. Dominici, J. Coursac, D. Dockery, J. Schwartz, and A. Zanobihi. 2000. National morbidity, mortality and air pollution study. Part II. Health Effects Institute, Cambridge MA. (Available at http://www.healtheffects.org.) (Verified Dec. 2000).

Shprentz, D. 1996. Breath-taking: Premature mortality due to particulate air pollution in 239 American cities. Nat. Resour. Defense Council, May, 1996. Available at http://www.nrdc.org. (Viewed Dec., 2000).

USEPA. 1996. Air quality criteria for particulate matter. Executive Summary. USEPA 600/P95/001aF. (Available online at http://www.epa.gov/ORD/WebPubs/execsum.html) (Verified Dec., 2000).

USEPA. 1996b. Air quality index: A guide to air quality and your health. Available at http://www.epa. gov/airnow/agibroch/agi.html (Verified Dec., 2000.).

USEPA. 1997. Quality assurance handbook for air pollution measurement systems. Vol. II. Ambient Air Specific Methods. USEPA 600/4-77-027a. May, 1977. Research Triangle Park, NC.

USEPA. 1998. 1997 National air quality: Status and trends. Available at http://www.epa.gov/oar/ aqtrnd97/brochure/pm10.html (Verified, Dec. 2000).

USEPA. 1998b. National air quality and emissions trends report. USEPA 454?R-00-003. March, 2000. Research Triangle Park, NC. Available at http://www.epa.gov/airtrends (Verified Dec. 2000). 